\title{
Spatial-temporal calculation simulation of ecological footprint of resource and environmental pollution in green communication
}

\author{
Roulin Chen, Duanmin Zhang and Bo Li
}

*Correspondence: jiutian898@163.com School of Economics and Management,

Changchun Normal University, Changhcun 130022, People's Republic of China

\begin{abstract}
As a quantitative evaluation method, the ecological footprint analysis (EFA) method is a frontier topic in the field of sustainable development. Human production activities will inevitably produce certain consumption, including the occupation of natural resources, resource consumption and waste production, which will have a certain impact on the ecological environment. This paper proposes to use the ecological footprint to inversely analyze the ecological environment and resource consumption, quantitatively convert the material consumption produced by human activities into the area of biological production land and compare it with the supply area of the study area. The EFA is used to reflect the changes in the indicators of regional sustainable development, and the regional sustainable development indicator system and analysis framework based on the ecosystem are constructed.The experimental result shows that the proposed model can effectively divide the resource space and at the same time can measure the degree of resource transfer, which has important guidance for revealing the internal relationship between regional ecological footprint characteristics and regional development and evolution significance.
\end{abstract}

Keywords: Ecological environment, Natural resource accounting, Ecological footprint model, Sustainable development, Green communication

\section{Introduction}

The sustainable development of the region must take the sustainable development of the ecological environment as the premise and guarantee, at present, the entire ecological sustainable development of industry is undergoing a "green communications" reform whirlwind with energy conservation, consumption reduction and emission reduction as the main directions. This is undoubtedly a great issue for the sustainable development of the green communications industry and the entire society [1]. The ecological environment not only is the carrying space of the social and economic activities in the region, but also provides the natural material foundation and the space for the waste disposal for the regional development. Therefore, as a decisive factor in regional development,

(c) The Author(s) 2020. Open Access This article is licensed under a Creative Commons Attribution 4.0 International License, which permits use, sharing, adaptation, distribution and reproduction in any medium or format, as long as you give appropriate credit to the original author(s) and the source, provide a link to the Creative Commons licence, and indicate if changes were made. The images or other third party material in this article are included in the article's Creative Commons licence, unless indicated otherwise in a credit line to the material. If material is not included in the article's Creative Commons licence and your intended use is not permitted by statutory regulation or exceeds the permitted use, you will need to obtain permission directly from the copyright holder. To view a copy of this licence, visit http:// creativecommons.org/licenses/by/4.0/. 
the sustainable development of the region requires comprehensive consideration of the regeneration and substitution capacity of regional resources, the recycling and purification capacity of life support systems and the protection of biodiversity. The ecological footprint model, which has been developing rapidly in recent years, not only can meet the above requirements, but also can be calculated intuitively and has regional comparability $[2,3]$. Therefore, the relevant international machines have been quickly obtained. The recognition of government departments and research institutions has become an important method in international sustainable development measurement $[4,5]$.

The specific contributions of this paper include:

1 This paper proposes to use ecological footprint to conduct a back analysis of the ecological environment and resource consumption.

2 Quantitatively convert the material consumption generated by human activities into the area of biological production land and compare it with the supply area of the study area.

3 On the timescale, the study of ecological footprint time series has been added to reveal the internal interaction mechanism between regional ecological footprint characteristics and regional development and evolution.

4. The ecological footprint analysis method is used to reflect the changes of regional sustainable development indicators, and the regional sustainable development indicator system and analysis framework based on the ecosystem are constructed.

The rest of this paper is organized as follows. Section 2 discusses the ecological footprint, followed by the method discussed in Sect. 3. The experiment is discussed in Sect. 4 . Section 5 concludes the paper with summary and future research directions.

\section{Ecological footprint}

Ecological footprint refers to the total area of land and water that can continuously provide certain people with all the resources they consume and absorb all the wastes they produce [6, 7]. EF's calculations are based on the following two facts: Humans are able to estimate most of the resources they consume, energy and the amount of waste they produce; these resources and wastes can be converted into ecologically productive areas for the production and consumption of these resources and wastes $[8,9]$. The main considerations are as follows: fossil energy land, cultivated land, woodland, pasture land, construction land and water area which are weighted to sum up the six kinds of biological production areas with different ecological productivity [10,11].

EF accounting formula:

$$
\mathrm{EF}=N \mathrm{ef}=\sum_{i=1}^{n}(r i c i / p i)
$$

in which $i$ is the type of consumption commodity and input; EF is the total ecological footprint; $N$ is the population number; ef is the per capita ecological footprint; it is the average balance factor; it is the per capita consumption of class I commodity; and it is the world average living ability of class I consumer goods [12, 13]. 


\subsection{The basic thought and hypothetical premise of ecological footprint research}

Ecological footprint refers to the biological productive land area (hereafter referred to as land area) needed to maintain resource consumption and absorb waste under given population and economic conditions $[14,15]$. The basic idea is to convert the "interest" (ecological footprint) of the natural assets needed by human consumption and the "interest" (ecological carrying capacity) generated by the natural assets into the land area which can be compared with each other. The comparison between the two is used to judge the overutilization of natural assets by human beings [16, 17]. To this end, there are six assumptions: (1) the annual consumption of available resources and the amount of waste generated; (2) the consumption and waste of most of the resources The material flow can be converted into land area; (3) various different types of land area can be given a certain weight and converted into a standardized global hectare unit (with the world average productive capacity); (4) all types of land use are exclusive, so the total demand can be obtained by adding up the area of resource utilization and waste absorption; (5) the total interest occupied by human activities can be compared directly with the interest provided by itself; and (6) aggregate demand may exceed total supply $[18,19]$.

\subsection{Calculation method of ecological footprint}

The ecological footprint calculation process is shown in Fig. 1.

It can be seen from Fig. 1 that the calculation method of ecological footprint can be divided into two parts: (1) converting human consumption and waste emissions into corresponding land area and (2) comparing ecological footprint and ecological carrying capacity with common standards. The first part is mainly through the establishment of the consumption-land conversion matrix [20,21]. It is relatively simple to convert the consumption of biological resources into the corresponding land area;

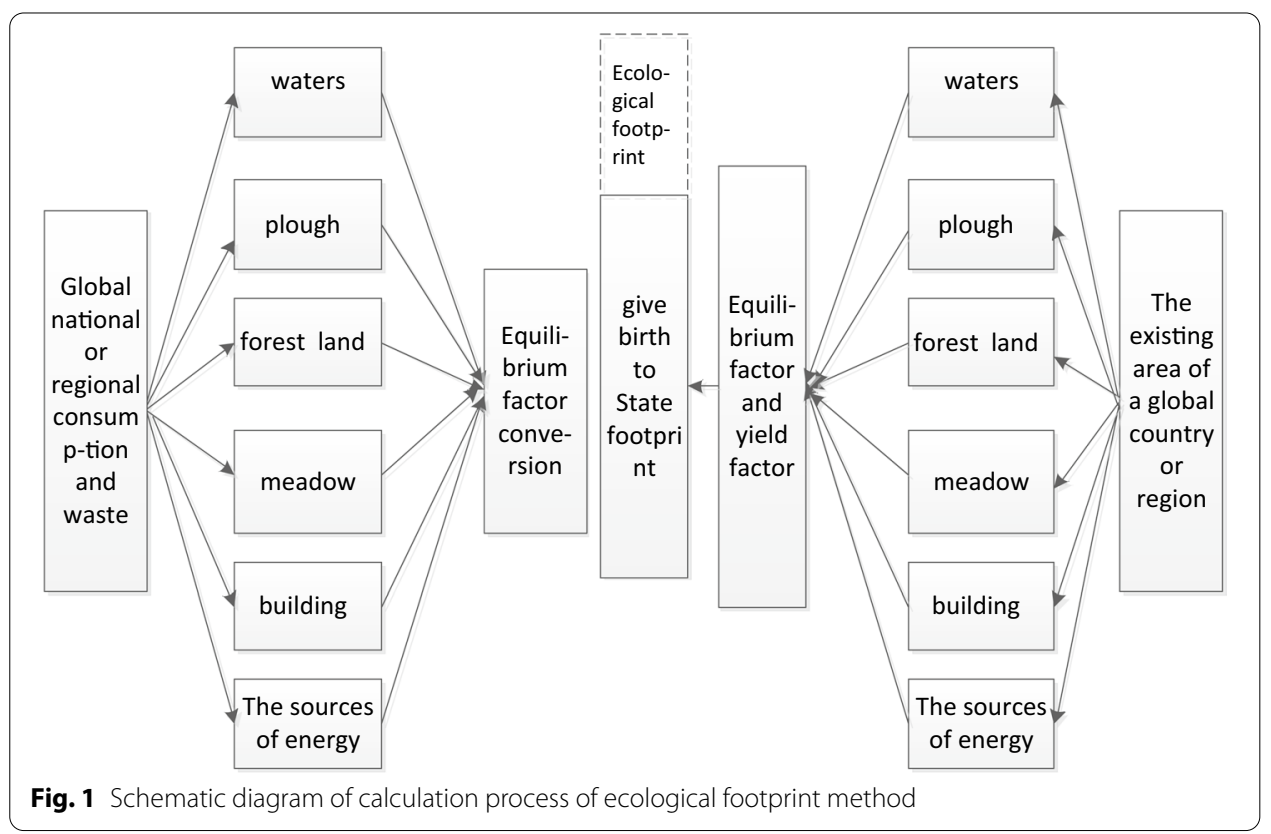


Table 1 Carbon uptake per unit area

\begin{tabular}{lllll}
\hline $\begin{array}{l}\text { Global forest area } \\
\left(\mathrm{Km}^{2}\right)\end{array}$ & $\begin{array}{l}\text { Aboveground dry } \\
\text { matter weight }(\mathbf{t} / \\
\left.\mathrm{Km}^{2} / \mathbf{a}\right)\end{array}$ & $\begin{array}{l}\text { Underground dry } \\
\text { matter weight }(\mathbf{t} / \\
\left.\mathbf{K m}^{2} / \mathbf{a}\right)\end{array}$ & $\begin{array}{l}\text { Total dry matter } \\
\text { weight }\left(\mathbf{t} / \mathbf{K m}^{2} / \mathbf{a}\right)\end{array}$ & $\begin{array}{l}\text { Total carbon } \\
\text { absorption }(\mathbf{t C} / \\
\left.\mathbf{k m}^{2} / \mathbf{a}\right)\end{array}$ \\
\hline $5120.227 \times 10^{6}$ & $11,612 \times 10^{6}$ & 2.27 & 2.84 & 1.42 \\
\hline
\end{tabular}

Table 2 Global average energy footprint

\begin{tabular}{lll}
\hline & Carbon emission factor & $\begin{array}{l}\text { Global average } \\
\text { energy footprint (Cj/ } \\
\left.\mathbf{K m}^{2} / \mathbf{a}\right)\end{array}$ \\
\hline Coal & 26 & 55 \\
Oil & 30 & 71 \\
Gas & 15.3 & 93 \\
\hline
\end{tabular}

only the embedding of the corresponding land area should be considered, that is, how much land area is needed for a given consumption quantity to produce and supply [22].

\subsection{The key points in the calculation of ecological footprint}

Land disposal of fossil energy: Usually, the exploitation and utilization of fossil energy means the depletion of stocks and the generation of waste gas. Therefore, in view of the development and utilization of fossil energy, the fossil energy land can be treated from the point of view of flow evaluation and the land area needed to provide the energy consuming substitute and absorb the waste gas [23]. Because the natural system has the obvious absorption ability to $\mathrm{CO}_{2}$ and the data are more abundant, this mainly deals with the waste gas of $\mathrm{CO}_{2}$. At present, it is mainly used to estimate the land area needed to absorb the new $\mathrm{CO}_{2}$ to calculate the demand for fossil energy land. The absorptive capacity of forests is calculated by calculating the average absorptive capacity of 26 different biota. The detailed calculation process is shown in Tables 1 and 2 .

\section{Method}

Ecological footprint model, as a method of accounting for natural resources from an ecological point of view, has experienced the development of one-dimensional model.

\subsection{Calculation method of ecological footprint model}

The formula for calculating the ecological footprint of the project is as follows:

$$
\mathrm{EF}=\mathrm{EF}_{\mathrm{C}}+\mathrm{EF}_{\mathrm{W}}
$$

in which $\mathrm{EF}_{\mathrm{c}}(\mathrm{C}=$ consumption $)$ is the ecological footprint of the consumption invested in the construction, operation and maintenance phase of the project. $\mathrm{EF}_{\mathrm{w}}$ ( $\mathrm{W}=$ waste) is the ecological footprint of the waste produced during the construction of the project. 


$$
\mathrm{EF}_{\mathrm{C}}=N \cdot \mathrm{ef}=N \cdot r j \cdot \sum_{i}^{n}(a b i)=N \cdot r j \cdot \sum_{i}^{n}\left[\frac{c i}{p i}\right]
$$

in which $N$ is the population of the project, ef is the ecological footprint per capita, $r j$ is the equilibrium factor $(j=1,2 \ldots 6)$ to indicate the land type and $a b i$ is the per capita bioproductive land area of the class I consumption project. $c i$ is per capita consumption for category $i$ projects, and $p i$ says average global production capacity for category $i$ projects.

With the construction of the project going on, there will be some waste. Every $1 \mathrm{~m}^{2}$ construction project in our country will produce about $60 \mathrm{~kg}$ waste. However, due to the lack of strict supervision and management of the treatment of Lakzaka in our country, construction waste is usually disposed of by direct stacking or landfill. The construction waste of each $1000 \mathrm{~kg}$ will occupy the land of $0.067 \mathrm{~m}^{2}$, so the calculation formula of the ecological footprint of construction waste is as follows:

$$
\mathrm{EF}_{\mathrm{W}}=S_{\mathrm{BA}} \times 60 \times 0.067 \times 10^{-3} .
$$

The calculation formula of ecological carrying capacity of the project is as follows:

$$
\mathrm{EC}=N \cdot e c=N \cdot e j \cdot y j \cdot \sum_{i=1}^{n} b i
$$

in which $e c$ is the per capita ecological carrying capacity, $e j$ is the equilibrium factor, $y j$ is the yield factor and $b i$ is the per capita biological productive land area.

According to the proposal of the (WCED) of the World Commission on Environment and Development, $12 \%$ of the area of bioproductive land should be set aside for biodiversity conservation, and the actual ecological capacity of the project should be multiplied by a coefficient of 0.88 . Namely,

$$
\mathrm{EC}=0.88 \mathrm{~N} \cdot e c .
$$

Calculation of ecological surplus:

The concept of surplus (ecological deficit) is defined as follows:

$$
\mathrm{ES}=\mathrm{EC}-\mathrm{EF} .
$$

If ES $>0$, there is ecological surplus, and the ecological carrying capacity of the project is higher than that of the sustainable improvement of the project. If $\mathrm{EF}<0$, there will be ecological deficit, the ecological carrying capacity of the project is not as good as the ecological footprint, the sustainability of the project is poor, and the project is in a critical state between sustainability and unsustainability, such as $\mathrm{ES}=0$.

\subsection{Three-dimensional ecological footprint model}

On the basis of two-dimensional model, Niccolucci has introduced two new indexes, footprint depth and footprint breadth, to describe the ecological footprint by the volume of the cylinder, so as to explain the human occupation of the natural resource flow and the natural resource stock. The plane analysis of the two-dimensional model 
is extended to the stereoscopic analysis of the three-dimensional model, and the longitudinal expansion of the ecological footprint research is realized. Compared with the two-dimensional model, the concept of natural resource stock is introduced in the three-dimensional model. The stock of natural resources is relative to the flow of natural resources; when the flow of natural resources cannot meet human consumption, additional consumption comes from the stock of natural resources. The evolution of the ecological footprint model from two to three dimensions is shown in Fig. 2.

There are the following relationships in the 3D model:

$$
\mathrm{EF}=\mathrm{BC}+\mathrm{ED}
$$

in which $\mathrm{EF}$ is the ecological footprint; $\mathrm{BC}$ is the area of ecologically productive land that can be provided by region; and ED is the ecological deficit.

In a three-dimensional model, there are the following relationships:

$$
\begin{aligned}
& 0 \prec \mathrm{EF}_{\text {Size }} \leq \mathrm{BC} \\
& \mathrm{EF}=\mathrm{EF}_{\text {Size }} \times \mathrm{EF}_{\text {Depth }} \\
& \mathrm{EF}_{\text {Depth }}=1+\frac{\mathrm{EF}-\mathrm{BC}}{\mathrm{BC}} .
\end{aligned}
$$

In the three-dimensional model, when the ecological footprint is smaller than the ecological carrying capacity, the footprint breadth is used to characterize the extent of human activity occupying the natural resource flow. It can be concluded that footprint depth is an indicator of regional ecological pressure on a timescale.

\subsection{Research progress in ecological footprint model}

According to 175 related research papers which have been retrieved at present, the research on ecological footprint in China is mainly focused on three aspects, that is, model review, scale footprint research and specific industry/sector footprint analysis. The comparison of the content and quantity of China's ecological footprint research is shown in Fig. 3.

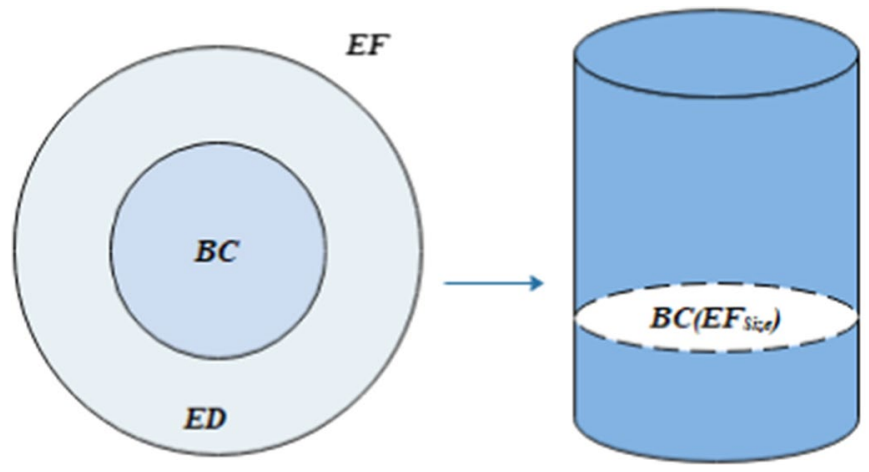

$E F_{\text {Degh }}$

Fig. 2 Evolution of ecological footprint model from two to three dimensions 


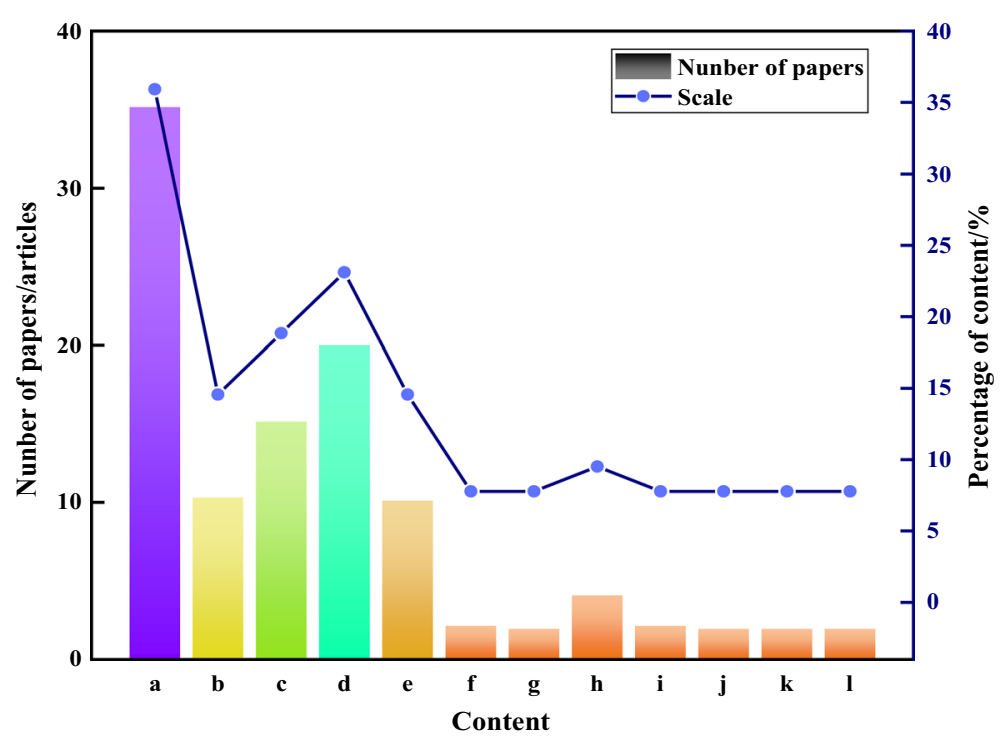

Fig. 3 Comparison of content and quantity of ecological footprint studies in China

\section{Experiment}

Spatial and temporal analysis of ecological footprint and ecological carrying capacity of water resources in China was performed.

China has a vast territory and is affected by many climatic types, and there is a serious phenomenon of uneven distribution of water resources in time and space. In recent years, water pollution is becoming more and more serious. Under the influence of monsoon climate, the total amount of water resources is abundant in most areas of China, but there is a serious imbalance in spatial distribution, which decreases from the southeast coast to the northwest inland. The difference in time distribution is also large; most areas have less spring and winter rain and more summer and autumn rain. The spatial and temporal differences of ecological footprint and ecological carrying capacity of water resources in China from 1997 to 2010 were studied in order to improve the planning and management of water resources in China. For a certain reference basis, promote the sustainable development of China's social and economic environment.

\subsection{Ecological footprint model of water resources}

It is divided into three major users: domestic water, production water and ecological and environmental water supply (including only urban environmental water supplied by artificial measures and some rivers and lakes, wetland water). The calculation model is as follows:

$$
\begin{aligned}
& \mathrm{EF}_{\mathrm{W}}=N \times \mathrm{ef}_{\mathrm{w}}=\gamma_{\mathrm{w}} \times W / P_{\mathrm{w}} \\
& \mathrm{ef}_{\mathrm{w}}=\gamma_{\mathrm{w}} \times W_{\text {cap }} / P_{\mathrm{W}}
\end{aligned}
$$

in which $\mathrm{EF}_{\mathrm{w}}, N, \mathrm{Ef}_{\mathrm{w}}, \gamma_{\mathrm{w}}, P_{\mathrm{w}}, W$ and $W_{\text {cap }}$ are the total ecological footprint of water resources $\left(\mathrm{hm}^{2}\right)$, the number of population, the ecological footprint of water 
resources per person ( $\mathrm{hm}^{2} /$ person), the global equilibrium factor of water resources, the global average production energy of water resources $\left(\mathrm{m}^{3} / \mathrm{hm}^{2}\right)$, total water consumption $\left(100 \mathrm{~m}^{3}\right)$ and per capita water consumption $\left(\mathrm{m}^{3}\right)$, respectively [15].

The ecological carrying capacity of water resources refers to the ability of the highest value of water supply to maintain the normal operation of economic system and ecosystem in a certain period of time and in a certain region. It also has natural attributes, social attributes and spatial attributes.

$$
\mathrm{EC}_{\mathrm{w}}=N \times e c_{\mathrm{w}}=0.4 \times \psi \times \gamma_{\mathrm{w}} \times Q / P_{\mathrm{w}} .
$$

As $60 \%$ of the water carrying capacity of a region and a country is used to maintain the ecological environment, the water carrying capacity must be multiplied by a factor of 0.4; ECw, ecw, $\gamma_{w}, \psi, \mathrm{Q}, \mathrm{Pw}$ and $\mathrm{N}$ are water resource carrying capacity $\left(\mathrm{hm}^{2}\right)$, per capita water resource carrying capacity $\left(\mathrm{hm}^{2} /\right.$ person), global equilibrium factor of water resources, output factor of regional water resource source, total water resource amount $\left(\mathrm{m}^{3}\right)$, global average water production capacity $\left(\mathrm{m}^{3} / \mathrm{hm}^{2}\right)$ and population, respectively.

The correlation coefficient is a statistical analysis indicator of the degree of correlation between variables, and its formula is as follows:

$$
r_{\mathrm{ER}}=\frac{\sum\left(\mathrm{EC}_{\mathrm{W}}-\overline{\mathrm{EC}_{\mathrm{W}}}\right)(\mathrm{RF}-\overline{\mathrm{RF}})}{\sqrt{\sum\left(\mathrm{EC} C_{\mathrm{W}}-\overline{\mathrm{EC}}\right)^{2}} \sqrt{\sum(\mathrm{RF}-\overline{\mathrm{RF}})^{2}}}
$$

in which RER, $\mathrm{EC}_{\mathrm{w}}$ and $\mathrm{RF}$ are the correlation coefficient between the ecological carrying capacity of water resources and precipitation, the ecological carrying capacity of water resources $\left(\mathrm{hm}^{2}\right)$, the mean value of ecological carrying capacity of water resources $\left(\mathrm{hm}^{2}\right)$ and the value of precipitation $(\mathrm{mm})$, in each year, and mean precipitation per year $(\mathrm{mm})$

RMB 413,000 GDP Water Resources Ecological footprint.

This indicator can be used to measure the utilization of water resources, with the following formulas:

Water resources ecological surplus (deficit) $=\mathrm{EC}_{\mathrm{W}}-\mathrm{EF}_{\mathrm{W}}$.

When the results of $\mathrm{EC}_{\mathrm{w}}-\mathrm{EF}_{\mathrm{w}}$ are greater than, equal to, less than 00:00, the water resources show ecological surplus, ecological balance and ecological deficit, respectively.

\subsection{Results}

The ecological footprint and ecological carrying capacity of water resources in China are calculated. The results are shown in Fig. 4. It can be seen from the figure that the annual variation of the ecological carrying capacity of water resources in China is great, and the maximum value of the ecological carrying capacity of water resources appears in 1998, reaching 21.1. A minimum of 100 million $\mathrm{hm}^{2}$; was seen in 2004 and 2009, with only 1.5 billion $\mathrm{hm}^{2}$, down $28.5 \%$. By calculation, the ecological carrying capacity of water resources has a great correlation with precipitation, and the correlation coefficient is $0.5 \%$. During the analysis period, China's water resources showed a certain ecological surplus in Fig. 4, and there was also a certain amount of growth. State space is available for use. The ecological footprint of GDP water resources in China has declined (Fig. 6), 


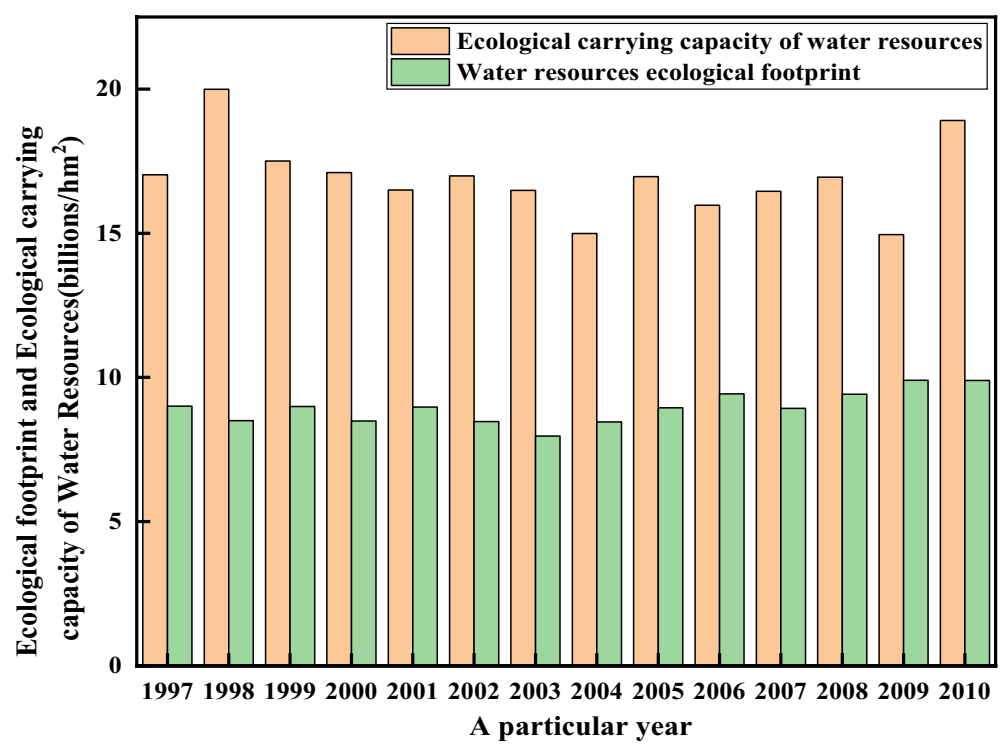

Fig. 4 Ecological footprint and ecological carrying capacity of water resources in China 1997-2010

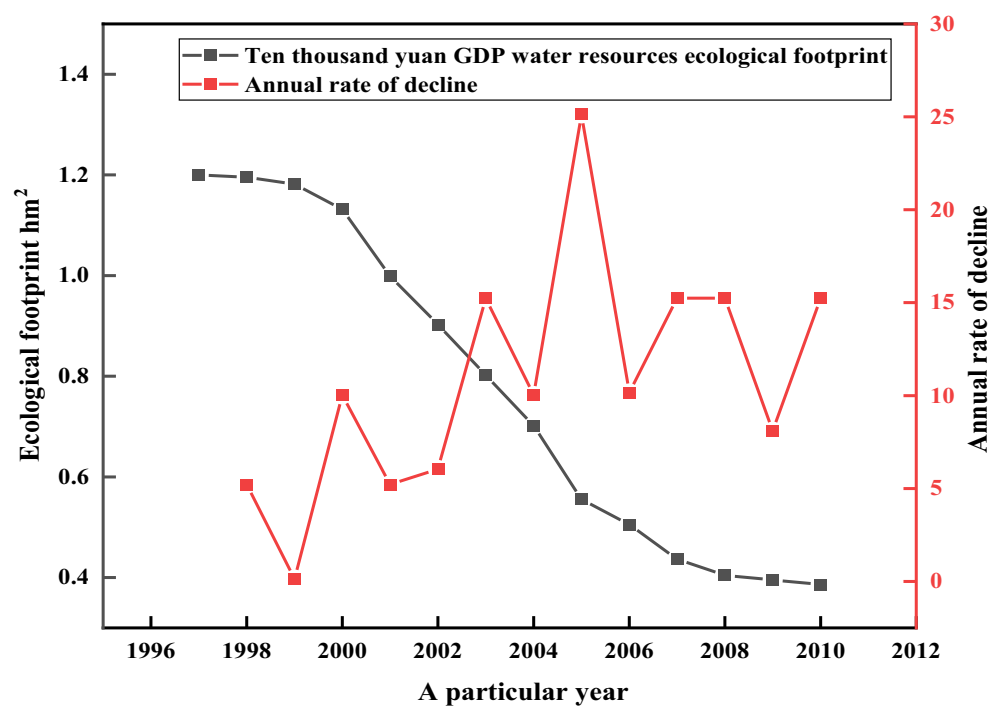

Fig. 5 Ecological footprint of GDP water resources in China from 1997 to 2010

from $1.5 \%$ in 1997 , an annual decrease of $11.1 \%$. The utilization rate of water resources in China is increasing year by year.

The water resource utilization of a region or a country can be judged by comparing the relationship between the ecological carrying capacity of water resources per capita and the ecological footprint $\left(\mathrm{hm}^{2}\right)$ in Fig. 5. The ecological footprint of water resources per capita in China from 1997 to 2010 was maintained at $0.0 .68-0.76 \mathrm{hm}^{2} /$ person, which showed the trend of first decreasing and then rising, the highest value appeared in 1997, and the lowest value appeared in 2003. The relative change of ecological carrying capacity of water resources per capita is relatively large, which is closely related to the amount 


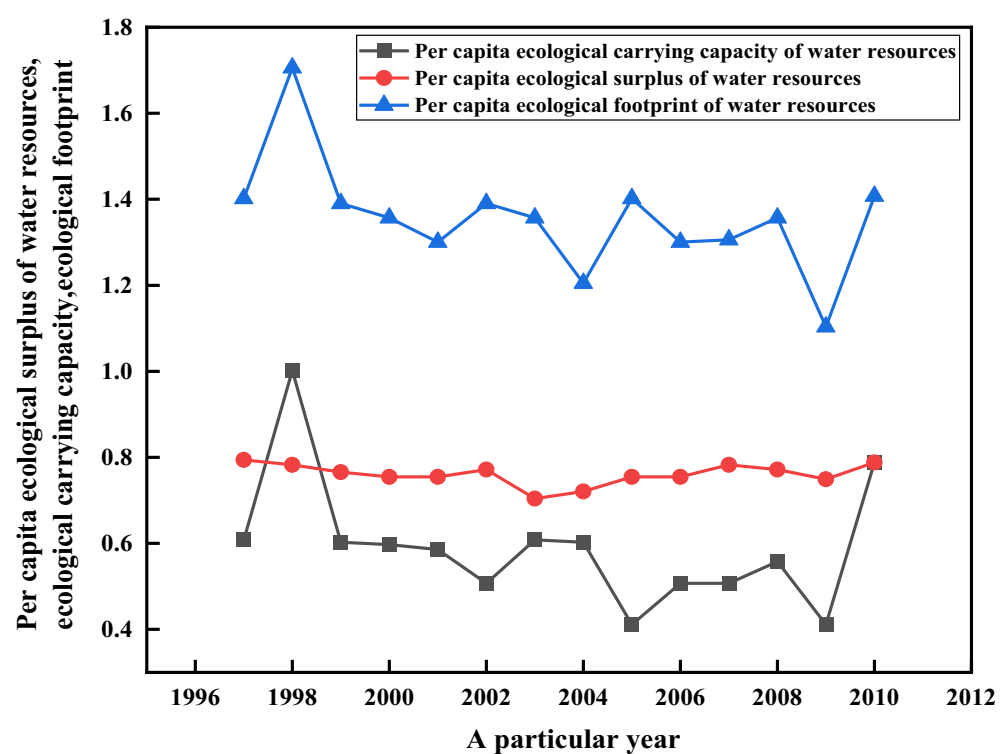

Fig. 6 Ecological footprint, ecological carrying capacity and ecological surplus of per capita water resources in China, 1997-2010

of precipitation in the current year. The highest value appeared in 1998, reaching $1.5 \%$. $69 \mathrm{hm}^{2} /$ person. It was mainly affected by three heavy precipitation processes in the Yangtze River basin in that year, and the lowest value appeared in 2009, which was only $1.5 \%$. The change trend of ecological surplus of per capita water resources is close to the trend of ecological carrying capacity, and the highest value appears in 1998, reaching $0.5 \% .97 \mathrm{hm}^{2} /$ person, the lowest in 2009 , was just $0.5 \% .39 \mathrm{hm}^{2} /$ person, still have ecological surplus, can further develop and utilize. The per capita ecological surplus of water resources has generally shown a downward trend, indicating that China's water demand is increasing, while climate change leads to changes in precipitation and water pollution. Changes in vegetation have also reduced the amount of water available in China.

In the ecological footprint account of water resources in China from 2003 to 2010, the agricultural water consumption was the largest, and the ecological footprint was maintained at $0.0 .44 \mathrm{hm}^{2} /$ person and 0 . The per capita ecological footprint of water resources fluctuated greatly between $46 \mathrm{hm}^{2} /$ person, which was the largest in 2006 and 2009, which was $0.5 \% .46 \mathrm{hm}^{2} /$ person, the smallest in 2003 , was just $0.5 \% .44 \mathrm{hm}^{2} /$ person, accounting for an average of $62.2 \%$ of the total water account. Industrial water and domestic water accounted for $23.3 \%$, respectively, $175 \%$ and $12.5 \%$. The ecological footprint of industrial water use is maintained at $0.15 \mathrm{hm}^{2} /$ person and 0 . Between $18 \mathrm{hm}^{2} /$ person, domestic water is maintained at $0.5 \% .081 \mathrm{hm}^{2} /$ person and $0.094 \mathrm{hm}^{2} /$ person, showing a slow upward trend, ecological and environmental water supply only $1.5 \%$. The range of changes over the years is $0.1 \% .01 \mathrm{hm}^{2} /$ person to $0.015 \mathrm{hm}^{2} /$ person. In general, the ecological footprint of water resources of each production account is increasing (Fig. 6), and the water demand of each account is increasing (Fig. 7).

The ecological footprint of ten thousand yuan GDP water resources can reflect the utilization rate of water resources. It can be seen from Fig. 8 that GDP water resources of ten thousand yuan are the lowest in Beijing and Tianjin, and the water 


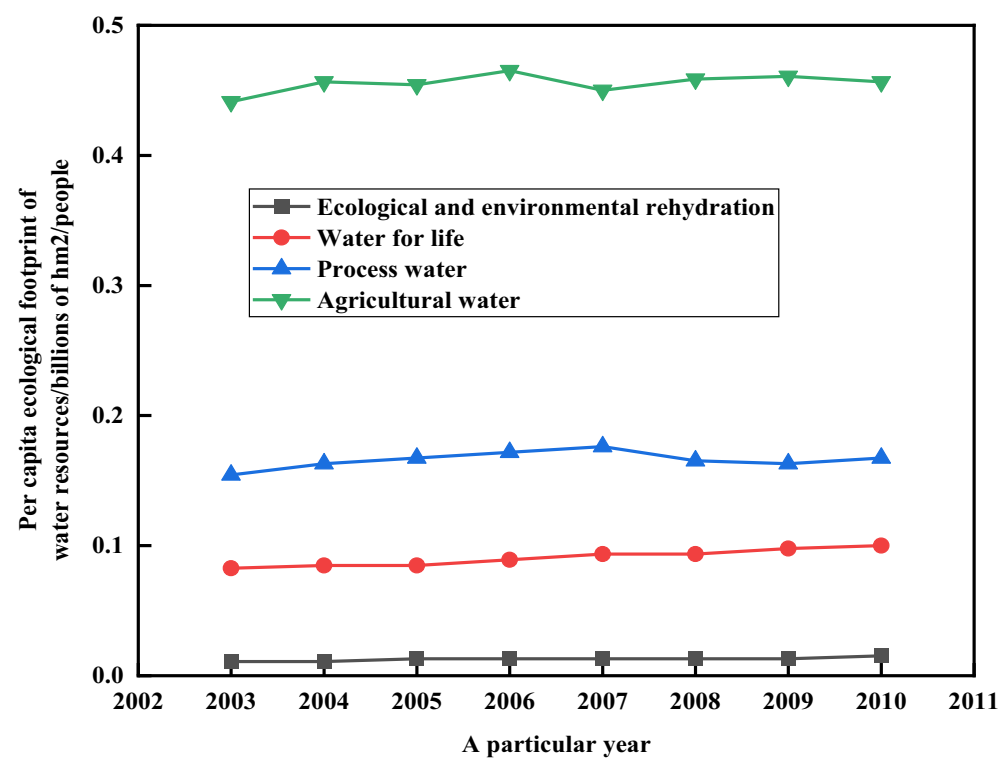

Fig. 7 Ecological footprint of water resources per capita in different production accounts in China, 1997-2010

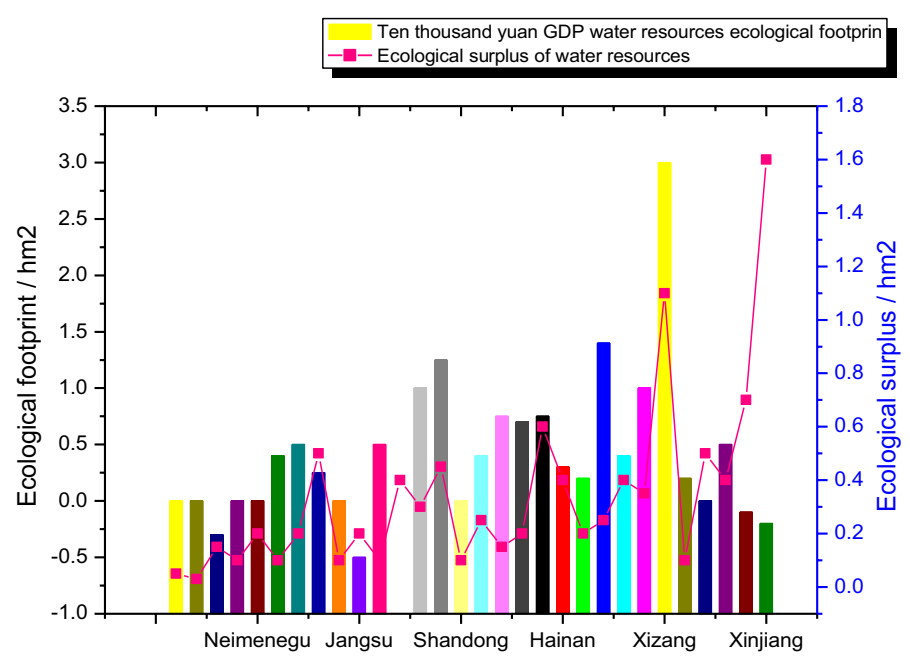

Provinces (autonomous regions, municipalities directly under the Central Government)

Fig. 8 National GDP water ecological footprint and ecological surplus

resources have been fully utilized. Xinjiang is the highest, mainly because of the economic structure and other factors; one of the characteristics of water use in Xinjiang is that the proportion of agricultural water use is too high, accounting for $95 \%$ of the total water consumption. Tibet took the second place, which was mainly related to industrial structure, water-saving level and water resources. 


\section{Discussion}

At present, domestic ecological footprint research has made gratifying progress, but there is still a big gap compared with outside countries. According to the study of domestic ecological footprint, compared with the frontier research fields and trends of ecological footprint abroad, the research on domestic ecological footprint and sustainable development in the future should be strengthened in the following four aspects. The main contents are as follows:

1 On the timescale, the study on the time series of ecological footprint is increased to reveal the internal interaction mechanism between the characteristics of regional ecological footprint and the evolution of regional development, as well as the corresponding coupling relationship between the change of regional ecological footprint and the regional sustainable development.

2 On the spatial scale, we should increase the comparative study of the ecological footprint in the east, middle and west regions of China, large, medium, small cities, cities and villages and analyze the structural hierarchy of the ecological footprint.The differences of validity rate, temporal dynamics, spatial superposition and spatial diffusion reveal the relationship between regional development and interregional, intercontinental and even global, and discuss the spatial segmentation scale and degree of regional ecological footprint spillover and transfer. The "mark value" of ecological footprint under the ecological ethics equity of regional development can better reveal the inner nature of regional development and regional and even global sustainable development relationship.

3 On the one hand, we should strengthen ecological footprint and ecological compensation, ecological footprint and ecological security, ecological footprint and environmental ethics, the time series of ecological footprint, the different spatial scale comparison of ecological footprint, the ecological footprint of waste materials, the limiting factors of regional development capacity, the ecological footprint of circular economy and so on; on the other hand, we should strengthen the relationship between different consumption patterns, consumption level, ecological footprint in the context of consumption culture and regional sustainable development, and international trade. The inter-regional migration of ecological footprint is caused by domestic trade and the inter-regional diffusion of ecological responsibility, energy, transportation, aquaculture and industry. The research on ecological footprint of specific industries and departments, such as agriculture and tourism, will expand the research field of ecological footprint.

4 On the one hand, the improvement of ecological footprint calculation method should be strengthened, such as regional hectare, yield factor, equilibrium factor, land type, trade adjustment, energy consumption and waste absorption. On the other hand, the ecological footprint analysis method should be combined with other indicators that can reflect the sustainable development of the region in terms of social economy and economy, and the index system and the analysis frame of the regional sustainable development based on the ecological footprint should be established. Vigorously developing HANPP (human appropriation of net primary production) analysis strengthen the ecological footprint based on PIOTs (physical input_output Tables) 
rather than MIOTs (monetary input_output Tables), ecological burden research, promote regional and global sustainable development.

\author{
Abbreviation \\ EFA: Exploratory factor analysis.
}

\title{
Acknowledgements
}

This study was supported by Research Fund for the Doctoral Program of Changchun Normal University; Social Science Fund Project of Changchun Normal University "Research on collaborative mechanism and development strategy of green agriculture in Jilin Province: From the perspective of innovation value sharing"; Science and technology research and planning project of Jilin Provincial Education Department "Research on the innovation and development mode and strategy of green agriculture industry in Jilin Province".

\section{Authors' contributions}

Roulin Chen is responsible for the writing of the paper, Duanmin Zhang is responsible for the collection of experimental data, and Bo Li is responsible for the design of the experimental process. All authors read and approved the final manuscript.

\section{Funding}

This study was supported by Research Fund for the Doctoral Program of Changchun Normal University; Social Science Fund Project of Changchun Normal University "Research on collaborative mechanism and development strategy of green agriculture in Jilin Province: From the perspective of innovation value sharing"; Science and technology research and planning project of Jilin Provincial Education Department "Research on the innovation and development mode and strategy of green agriculture industry in Jilin Province".

\section{Availability of data and materials}

Data sharing is not applicable to this article as no datasets were generated or analyzed during the current study.

\section{Ethical approval}

This article does not contain any studies with human participants or animals performed by any of the authors.

\section{Informed consent}

All authors agree to submit this version and claim that no part of this manuscript has been published or submitted elsewhere.

\section{Competing interests}

The authors declare that they have no conflict of interest.

Received: 29 July 2020 Accepted: 2 December 2020

Published online: 14 December 2020

\section{References}

1. E. William, Ecological footprints and appropriated carrying capacity: what urban economics leaves out. Environ. Urban. 6(2), 121-130 (1992)

2. M. Xu, D. Cheng, Q. Zhang, A resolution to the conception of ecological footprint Table. China Popul. Resources Environ. 16(6), 69-78 (2006)

3. D. Daniel, C. Mathis, Trading spaces: calculating embodied Ecological Footprints in international trade using a Product Land Use Matrix (PLUM) Table. Ecol. Econ. 68(3), 1938-1951 (2009)

4. S. Hall, B. Poller, C. Bailey, S. Gregory, R. Clark, P. Roberts, A. Tunbridge, V. Poran, C. Evans, B. Crook, Use of UV fluorescence-based simulation in evaluation of personal protective equipment worn for first assessment and care of a patient with suspected high consequence infectious disease. J. Hosp. Infect. 23(6), 13-24 (2018)

5. R. Gupta, A. Kumari, S. Tanwar, N. Kumar, Blockchain-envisioned Softwarized multi-swarming UAVs to tackle COVID19 situations. IEEE Netw. 12(9), 215-225 (2020)

6. S. Elena, G. Olga, S. Vasiliy, S. Alexey, Developing of the decision tree algorithm using biomarkers panel for the differential diagnosis of primary glomerulonephritis. Nephrol. Dial. Transplant. 212(18), 123-134 (2019)

7. C. Chen, J. Wu, H. Lin, W. Chen, Z. Zheng, A secure and efficient blockchain-based data trading approach for internet of vehicles. IEEE Trans. Veh. Technol. 229(12), 1-12 (2019)

8. Z. Bo, W. Xuan, Z. Dongbo, S. Chanan, Z. Jianhua, Hybrid probabilistic-possibilistic approach for capacity credit evaluation of demand response considering both exogenous and endogenous uncertainties. Appl. Energy 229(12), $186-200(2018)$

9. F. Long, N. Xiong, A.V. Vasilakos, L.T. Yang, F. Sun, A sustainable heuristic QoS routing algorithm for pervasive multilayered satellite wireless networks. Wireless Netw. 16(6), 1657-1673 (2010)

10. Y. Wang, L. Wang, A review of research on ecological footprintTable. Sci. Soil Water Conserv. 9(3), 114-120 (2011)

11. S. Schneider, M. Leyer, M. Tate, The transformational impact of Blockchain technology on business models and ecosystems: a symbiosis of human and technology agents. IEEE Trans. Eng. Manag. 11(9), 1-12 (2020) 
12. O.P. Sangoro, T. Gavana, M. Finda, W. Mponzi, F.O. Okumu, Evaluation of personal protection afforded by repellenttreated sandals against mosquito bites in south-eastern Tanzania. Malaria J. 7(13), 111-123 (2020)

13. D.C. Owen, M.T. Bensi, A.P. Davis, A.H. Aydilek, Measuring soil coverage using image feature descriptors and the decision tree learning algorithm. Biosyst. Eng. 196(1), 112-126 (2020)

14. H. Narayanan, M. Sokolov, A. Butté, M. Morbidelli, Decision tree-PLS (DT-PLS) algorithm for the development of process: specific local prediction models. Biotechnol. Prog. 35(4), 13-24 (2019)

15. C. Lin, N. Xiong, J.H. Park, T. Kim, Dynamic power management in new architecture of wireless sensor networks. Int. J. Commun Syst 22(6), 671-693 (2009)

16. J. Li, N. Xiong, J.H. Park, C. Liu, M.A. Shihua, S. Cho, Intelligent model design of cluster supply chain with horizontal cooperation. J. Intell. Manuf. 23(4), 917-931 (2012)

17. W. Guo, N. Xiong, A.V. Vasilakos, G. Chen, C. Yu, Distributed k-connected fault-tolerant topology control algorithms with PSO in future autonomic sensor systems. Int. J. Sens. Netw. 12(1), 53-62 (2012)

18. Z. Chen, D. Chen, Y. Zhang, X. Cheng, M. Zhang, C. Wu, Deep learning for autonomous ship-oriented small ship detection. Saf. Sci. 130, 104812 (2020)

19. Z. Huang, X. Xu, J. Ni, H. Zhu, C. Wang, Multimodal representation learning for recommendation in Internet of Things. IEEE Internet Things J. 6(6), 10675-10685 (2019)

20. H. Liang, J. Zou, K. Zuo, K. Muhammad Junaid, An improved genetic algorithm optimization fuzzy controller applied to the wellhead back pressure control system. Mech. Syst. Signal Process. 142, 106708 (2020)

21. H. Liang, D. Zou, Z. Li, K. Muhammad Junaid, Y. Lu, Dynamic evaluation of drilling leakage risk based on fuzzy theory and PSO-SVR algorithm. Future Gen. Comput. Syst. 95, 454-466 (2019)

22. Y. Zhang, R. Zhu, Z. Chen, J. Gao, D. Xia, Evaluating and selecting features via information theoretic lower bounds of feature inner correlations for high-dimensional data. Eur. J. Oper. Res. (2020). https://doi.org/10.1016/j. ejor.2020.09.028

23. H. Liang, A. Xian, M. Min Mao, P. Ni, H. Wu, A research on remote fracturing monitoring and decision-making method supporting smart city. Sustain. Cities Soc. 62, 102414 (2020)

\section{Publisher's Note}

Springer Nature remains neutral with regard to jurisdictional claims in published maps and institutional affiliations.

\section{Submit your manuscript to a SpringerOpen ${ }^{\odot}$ journal and benefit from:}

- Convenient online submission

Rigorous peer review

- Open access: articles freely available online

- High visibility within the field

- Retaining the copyright to your article

Submit your next manuscript at $\gg$ springeropen.com 